\title{
Treatment provision for adults with ADHD during the COVID-19 pandemic: an exploratory study on patient and therapist experience with on-site sessions using face masks vs. telepsychiatric sessions
}

Helen Wyler ${ }^{1 *+}$, Michael Liebrenz ${ }^{1 \dagger}$, Vladeta Ajdacic-Gross ${ }^{2}$, Erich Seifritz ${ }^{2}$, Susan Young ${ }^{3,4}$, Pascal Burger $^{2}$ and Anna Buadze ${ }^{2}$

\begin{abstract}
Background: Maintaining the therapeutic care of psychiatric patients during the first wave of the COVID-19 pandemic in Switzerland required changes to the way in which sessions were conducted, such as telepsychiatric interventions or using face masks during on-site sessions. While little is known about how face masks affect the therapeutic experience of patients and therapists, the effectiveness of telepsychiatry is well documented for several psychiatric disorders. However, research on the benefits of telepsychiatry in adult patients with attention-deficit/ hyperactivity disorder (ADHD) remains scarce. This seems problematic since the symptoms typically associated with ADHD, such as attention problems and distractibility, may lessen the utility of telepsychiatry for this particular group. The present study's aim was to explore how adult patients with ADHD and their therapists experienced therapy sessions during the COVID-19 pandemic in three different settings: face-to-face with the therapist wearing a face mask, via telephone, or via videoconferencing.

Methods: In this exploratory, quantitatively driven mixed-method study (quantitative questionnaire data and qualitative data from open-ended responses), we assessed patients' evaluation of the session, their treatment satisfaction, and patients' and therapists' ratings of therapeutic alliance. We also collected qualitative comments on both sides' experience of the session. Overall, 97 therapist and 66 patient questionnaires were completed. Results are reported for the $N=60$ cases for which data from both parties were available. Sequential multiple regressions adjusted for therapist and number of sessions were used for the main quantitative analyses.
\end{abstract}

(Continued on next page)

\footnotetext{
* Correspondence: helen.wyler@fpd.unibe.ch

${ }^{\dagger}$ Helen Wyler and Michael Liebrenz are co-first authors on this work.

'Department of Forensic Psychiatry, Institute of Forensic Medicine, University of Bern, Bern, Switzerland

Full list of author information is available at the end of the article
}

(c) The Author(s). 2021 Open Access This article is licensed under a Creative Commons Attribution 4.0 International License, which permits use, sharing, adaptation, distribution and reproduction in any medium or format, as long as you give appropriate credit to the original author(s) and the source, provide a link to the Creative Commons licence, and indicate if changes were made. The images or other third party material in this article are included in the article's Creative Commons licence, unless indicated otherwise in a credit line to the material. If material is not included in the article's Creative Commons licence and your intended use is not permitted by statutory regulation or exceeds the permitted use, you will need to obtain permission directly from the copyright holder. To view a copy of this licence, visit http://creativecommons.org/licenses/by/4.0/ The Creative Commons Public Domain Dedication waiver (http://creativecommons.org/publicdomain/zero/1.0/) applies to the data made available in this article, unless otherwise stated in a credit line to the data. 
(Continued from previous page)

Results: No statistically significant differences regarding session flow, post-session positivity, satisfaction and therapeutic alliance were observed. The only exception was that telepsychiatric sessions were rated as significantly less deep than face-to-face sessions, an effect that may decline over time, especially in the videoconferencing group. Patients and therapists identified similar facilitating and complicating aspects, but differed in their emphasis of specific elements.

Conclusions: Both settings, on-site with the therapist wearing a face mask and telepsychiatric, seem to be valid options to continue treatment of adults with ADHD during a situation such as the COVID-19 pandemic. Aspects such as patient preference, session content, and therapeutic methods may be useful to identify the most suitable modality.

Keywords: COVID-19 pandemic, Attention-deficit/hyperactivity disorder (ADHD), Telepsychiatry, Therapeutic alliance, Face mask, Face-to-face treatment, Videoconferencing, Telephone, Satisfaction

The first Swiss COVID-19 case was confirmed on the 24th of February 2020 [1]. On the 16th of March, the Swiss Federal Council declared an 'extraordinary situation' and introduced stringent regulations to slow down the spread of the virus (COVID-19 Ordinance 2 [2]) during the so-called first wave; citizens were advised to stay home whenever possible and gatherings of more than five individuals were prohibited shortly thereafter. The impact of the COVID-19 pandemic was not confined to people's working and social lives, however. First and foremost, it affected their access to health care, including psychiatric care. Following the declaration of the 'extraordinary situation', medical treatment providers, including psychiatrists and psychotherapists, were obliged by the government not to offer treatment that was not considered to be medically urgent in order to decelerate the spread of the virus [3]. At the same time, psychiatrists and psychotherapists had a duty to maintain psychiatric and psychotherapeutic care of the Swiss population by delivering indicated treatment that could not be delayed (see e.g. [4]).

To cope with this dilemma, both the society of Swiss psychiatrists - the Foederatio Medicorum Psychiatricorum et Psychotherapeuticorum [5] - and the Confederation of Swiss Psychologists [6] recommended that treatment via telephone or videoconferencing tools should be implemented and chosen over face-to-face sessions. In other words, psychiatrists and psychotherapists were advised to resort to telepsychiatric treatment whenever possible, even though this form of treatment provision was only partially reimbursed by health insurers [7]. If on-site treatment was necessary and unavoidable, significant changes to the course of a session had to be made. Based on the recommendations of the Federal Office of Public Health and the FMPP [8], the internal regulations of the outpatient clinic in which the present study was conducted included: (1) following hygiene rules before the session (supervised hand disinfection and temperature measurement including a check for symptoms of a possible COVID-19 infection at the entrance of the building), (2) observing distancing rules during the session, and (3) the therapist wearing a face mask during the session. ${ }^{1}$ Thus, continuing psychiatric or psychotherapeutic treatment during the COVID-19 pandemic required substantial changes to the way sessions were usually conducted, either by resorting to telepsychiatry or by making significant adjustments to on-site sessions including wearing face masks during therapy sessions.

\section{The use of face masks in face-to-face treatment}

While questions relating to the potential effects wearing face masks might have on therapy sessions and the therapeutic relationship have been discussed in recent Letters to the Editor [9-12] and discussion papers [13], little is known about their actual impact. A randomised controlled trial from Hong Kong in 2011, which examined patients' reaction to their general practitioner wearing a face mask during the consultation, found negative effects on patients' perception of the general practitioner's empathy, an effect that was more pronounced for more established general practitioner-patient relationships [14]. We are not aware of a study that has investigated psychiatric outpatients' experience of the session or the therapeutic relationship when the therapist is wearing a face mask.

\section{Telepsychiatry versus face-to-face therapy}

A main benefit of telepsychiatry - in this study defined as synchronous therapeutic interventions that are not delivered on-site - is often seen in its ability to provide access to care for patients who, for instance, live in rural or remote areas (see e.g. $[15,16])$. However, the COVID-19 pandemic highlighted the importance of

\footnotetext{
${ }^{1}$ At the time of data collection, wearing face masks during therapy sessions was not compulsory in Switzerland. However, as of late March 2020, the outpatient clinic made wearing a face mask mandatory for staff with direct patient contact to protect the patients.
} 
telepsychiatry in upholding provision of treatment independently of physical location in general. Additional advantages of telepsychiatry include cost-effectiveness [17], and, according to the experience of care providers, flexible scheduling and timely starts [18].

Over the past decades, the effectiveness of telepsychiatry has been examined in numerous studies. With respect to treatment outcome, empirical evidence suggests that telepsychiatry is on a par with face-to-face treatment for various psychiatric disorders [19], including anxiety disorder [20,21], depression [21], and post-traumatic stress disorder [22-24]. Also, patients seem to be as satisfied with tele-mental health interventions as they are with in-person treatment ([25], see also e.g. [26]). Some therapists, however, have expressed concerns that the lack of physical interaction in a telepsychiatric setting could hinder the development of a healthy therapeutic alliance (TA) (see e.g. [27]), which is often conceptualised as (1) an emotional bond between patient and therapist and (2) collaboration and consensus between the two parties on the goals and tasks of the therapy [28]. A thorough understanding of the impact of treatment modality on TA is essential given that TA has been found to be one of the strongest predictors of treatment outcome in face-to-face psychotherapy [29, 30], although the specific relevance of TA and its individual sub-components in telepsychiatric settings still warrants further investigation [31, 32].

Reviews of the literature suggest that concerns about TA in telepsychiatry may be unfounded. Patients' ratings of TA are fairly comparable for in-person and telepsychiatric interventions. In their review of video therapy treatment $(k=22)$, which included patient samples with a wide range of diagnoses including mixed anxiety and depression, posttraumatic stress disorder, and obsessivecompulsive disorders, Simpson and Reid summarised (p. 289): "TA ratings ( ...) were surprisingly homogenous across studies, and roughly equivalent to TA ratings for in-person therapy in those studies with a comparison group" [33]. Similarly, in a review on therapy delivered via telephone $(k=5$; diagnoses included in the reviewed studies were major depressive disorder, non-affective psychosis and no specified diagnosis), no statistically significant difference in TA ratings between the two modalities were reported [34], although results may have been influenced by the fact that most of the studies included used non-randomised opportunity samples. Interestingly, Simpson and Reid [33] reported that therapists did not rate TA quite as highly as their patients, especially in the early stages of treatment. Thus, some therapists seemed - at least initially - slightly more sceptical, whereas patients appeared to perceive TA similarly across the different treatment modalities.

\section{Attention-deficit/hyperactivity disorder (ADHD)}

ADHD is a highly inheritable [35] neuropsychiatric disorder [36] characterized by its core symptoms of inattention, impulsivity and hyperactivity and further accessory symptoms such as emotional over-reaction and affective lability [37]. The view of ADHD as a disease of youth that is outgrown in later life (see e.g. [37]) has had to be revised over the course of the last few decades. ADHD may persist either in a form that still meets the full criteria for a diagnosis of ADHD or in the form of clinically significant impairment associated with residual symptoms [38-41], as symptoms of hyperactivity and impulsivity generally tend to decrease with age [42]. The prevalence rate for ADHD up to the age of 18 is estimated at 5.3\% [36] and for adult ADHD at 2.5\% [43].

While ADHD is still highly prevalent in adulthood, it is also a severely underdiagnosed condition [44]. As recommended by the NICE guidelines [45], depending on the individual, a multimodal treatment, often including a combination of drug treatment and non-pharmacological treatment, should be offered. If left untreated, adult ADHD can be accompanied by severe functional impairments and limitations in multiple areas of life and is further associated with an increased risk of multiple mental health and social difficulties as well as premature mortality [46-50]. Some adults with ADHD succeed in developing coping strategies to mitigate the impact of their symptoms on their work and social life [51]. However, these strategies may no longer be sufficient in situations of exceptional stress, such as the COVID-19 pandemic, which severely disrupted people's everyday routine (e.g. introduction of home office or home schooling). It is therefore essential to ensure continuous availability of therapeutic support for patients with clinically relevant ADHD not only beyond childhood and adolescence, but also during such exceptional situations.

\section{Telepsychiatry for adults with ADHD}

In their recent review of the literature, Spencer and colleagues [52] identified 11 relevant primary studies with sample sizes of at least 20 participants investigating the use of telepsychiatry in patients with ADHD. Overall, the results were promising; telepsychiatry was both well accepted and valued by patients and also associated with improved outcomes. However, only one of the studies also included an adult sample. Moreover, telepsychiatry was used either to augment standard care (additional telepsychiatric sessions on evidence-based pharmacological care for ADHD and psychoeducation on the neurobiology of ADHD) or for consultation (virtual visits with psychiatrist or psychologist, who then consulted with the patient's primary care provider) or evaluation purposes, not as a (temporary) substitute for face-to-face treatment. 
The question of the suitability of telepsychiatric treatment for (adult) patients with ADHD seems particularly pertinent because of typical impairments associated with this disorder. On the one hand, patients might find it more difficult to stay focused during an off-site session due to the abundance of potential distractors in their environment. They may also find it difficult to cope with the demands of a telepsychiatric session in terms of time management and self-organisation, as these skills usually tend to be impaired in ADHD. Moreover, the setting in itself, using a media device like a smart phone or computer, might lead to patients carrying out activities simultaneously to the psychotherapeutic session. Thus, we see tangible risks for increased distractibility with this form of psychotherapy in this specific group of patients. On the other hand, however, in addition to the advantages of telepsychiatry already discussed above, telepsychiatric interventions could also counteract the negative effects of patients' disorganisation, e.g. by saving travel time and thus alleviating experiences of stress due to difficulties in time management [53]. Furthermore, adults with ADHD may experience a range of financial problems [54], and telepsychiatry would allow those affected to save on costs associated with traveling to the therapy sessions. Hence, further research on how this specific group of patients experience telepsychiatric care is necessary.

\section{The present study}

The aim of the present study was to explore how outpatients with ADHD and their therapists experienced therapy sessions under the adjustments necessary due to the COVID-19 pandemic. Each session took place either face-to-face with the therapist wearing a face mask, via videoconferencing, or via telephone; we subsume the latter two modalities under telepsychiatry. We intended to address two questions in particular. First, does telepsychiatric treatment offer a viable (temporary) alternative to face-to-face treatment in adult ADHD? As discussed, this question is important as several symptoms often associated with ADHD might result in telepsychiatry being particularly challenging for these patients. Second, how does on-site treatment with the therapist wearing a face mask compare to telepsychiatric treatment options? We are not aware of a comparative study investigating this question. Although explored in a specific group of patients, this examination of the impact of the therapist wearing a face mask will be of general interest.

Patients' and therapists' experience with the sessions were explored both quantitatively and qualitatively; each patient and therapist completed the questionnaire once during the assessment period with both questionnaires being completed for the same session. We assessed patients' experience and evaluation of the session, including their satisfaction with the therapy, and were also interested in patients' and therapists' ratings of TA. We further assessed whether patients felt the current sessions were comparable or inferior to the pre-COVID19 sessions and what setting they would prefer out of a number of different options. Finally, we asked patients and therapists about their experience of the session to obtain qualitative insights.

\section{Method \\ Study design}

This exploratory, quantitatively driven mixed-method study (combining quantitative questionnaire data and qualitative data from responses to open-ended questions [55-57];) with an independent measures design aimed to explore ADHD patients' and therapists' experience of a specific therapy session during the COVID-19 pandemic in one of the following three treatment modalities: face to face, videoconferencing, and telephone.

\section{Sample and recruitment}

Participants in this study were adults with a diagnosis of ADHD according to the 10th revision of the International Classification of Diseases [58], who were receiving treatment at a specialised outpatient clinic (multimodal therapy combining pharmacological therapy and psychotherapy, primarily for ADHD but - as per NICE guidelines [45] and the practice recommendations of the German Association for Psychiatry, Psychotherapy and Psychosomatics [59] - also for other neurodevelopmental or mental health conditions where appropriate). Data were collected between the end of April and the end of June $2020 .^{2}$ The type of treatment modality during the pandemic was determined based on each patient's needs and preferences. Patients were seen by the same therapist throughout the study. All patients with sufficient command of the German language and who attended a treatment session during the study period with one of the two participating therapists were offered the opportunity to participate in the research.

Overall, therapists completed 97 questionnaires. For 66 of these questionnaires a patient questionnaire was returned (response rate of 68\%). Data from six patients had to be excluded, either because essential information was missing $(n=3)$, their data were collected at a point at which the wearing of a face mask was not mandatory for therapists $(n=2)$, or because they did not have a diagnosis of ADHD $(n=1)$, yielding a final sample size of $N=60$ (face to face: $n=29$; videoconferencing: $n=$ 11 ; telephone: $n=20$ ). The two therapists involved in

\footnotetext{
${ }^{2}$ This means that most of the data collection took place during the extraordinary situation in Switzerland, which lasted from the 16th of March until the 19th of June.
} 
the study recruited similar numbers of patients (50 and 47) and had a similar response rate (66 and 70\%). Thirty-one patients from Therapist A and 29 patients from Therapist B were included in the final sample. The two therapists conducted similar numbers of face-toface and telepsychiatric sessions $(p=.993)$, although, at a descriptive level, Therapist A conducted more sessions over the phone (12 vs. 8 ) whereas Therapist B ran more videoconferencing sessions (7 vs. 4 ).

\section{Measures}

\section{Session evaluation questionnaire}

The Session Evaluation Questionnaire (SEQ [60]) is used to assess patients' self-reported immediate session experience. It consists of 21 items scaled according to a semantic differential (e.g. from 1 shallow to 7 deep). The factor structure of the English original was replicated in the German version for the factors session depth and session smoothness (both in-session processes) and post-session positivity (post-session impact), but not for arousal [61]. Therefore, arousal was not included in the present study. Studies that investigated construct validity reported statistically significant positive correlations with therapeutic alliance [61]. Higher scores indicate more depth, higher smoothness, and higher post-session positivity. Cronbach's alpha values in the current study were satisfactory to good with .70 (depth), .77 (smoothness), ${ }^{3}$ and .87 (post-session positivity).

\section{Client satisfaction questionnaire}

The Client Satisfaction Questionnaire (CSQ [62]) is an eight-item self-report scale that assesses patient satisfaction with the mental health services indicated by means of 4-point Likert-type responses. The German version of the CSQ [63] has been reported to be reliable (Cronbach's alpha $=.90)$ and to possess good psychometric properties overall [64]. The instructions were slightly adapted for the current study, stating "when answering the following questions, please consider the therapy sessions as they took place today". The mean score is reported with higher scores indicating higher satisfaction. Cronbach's alpha was good (.84).

\section{Working Alliance inventory}

The Working Alliance Inventory (WAI) is a common measure used to assess therapeutic alliance [33]. We applied the short revised version of the WAI for patients (WAI-SR-P) and therapists (WAI-SR-T) [65]. Both versions consist of 12 items; answers are provided on a 5point Likert scale ranging from seldom (1) to always (5).

\footnotetext{
${ }^{3}$ Due to a technical error, item 6 was missing from the questionnaire, which means that the subscale smoothness consisted of 4 instead of 5 items.
}

The German version of the WAI-SR-P has good internal consistency, with Cronbach's alpha ranging between .81 and .91 for the subscales [66, 67]. For the German version of the WAI-SR-T, only limited data are available; for this study, the 12-item version recommended by Munder [68] was used. The items of both WAI-SR questionnaires assess three subscales (bond, tasks, and goals). Mean scores are reported for each scale, with higher scores indicating a stronger working alliance. Cronbach's alpha values for the WAI-SR-P were acceptable to good for bond (.76) and tasks (.80), but questionable for goals (.66). As deleting an item on the scale did not improve Cronbach's Alpha, the scale was left unchanged. The corresponding values for the WAI-SR-T were acceptable at $.72, .72$, and .75 , respectively.

\section{Global assessment of functioning score}

The Global Assessment of Functioning (GAF) scale [69] was used to assess overall patient functioning from the therapist's perspective. The GAF score ranges from 1 to 100 , with 100 representing a high functioning individual that is not experiencing any symptoms.

\section{Questions regarding the patient's experience with the COVID-19 pandemic}

A self-developed four-item questionnaire was used to assess patient experience with the COVID-19 pandemic. Patients were asked (1) whether they belonged to the high-risk group (yes/no) and to indicate the extent to which (2) their everyday life was affected by the COVID19 pandemic, (3) they felt distressed because of the pandemic, and (4) they experienced fear because of the pandemic (all 5-point Likert-scales ranging from 1 not at all to 5 very much). The German questions and English translations can be seen from the Supplementary File 1 (Table A, questions C1-C4).

\section{Specific closed and open-ended questions regarding the session (patient questionnaire)}

Patients were asked whether they felt the current treatment modality was better, worse or comparable to the pre-COVID-19 therapy sessions, and how they would rank five treatment modality options (telephone; videoconferencing; face-to-face, in compliance with hygiene and distance rules; face-to-face with the therapist wearing a face mask; face-to-face with a plastic divider separating therapist and patient) in terms of preference if they had a free choice (see Supplementary File 1, Table A, questions F1 and F2). Moreover, patients were asked two open-ended questions: (1) "Was there anything you particularly liked about the way today's session took place?", and (2) "Was there anything you felt uncomfortable with or disliked about the way today's session took 
place?" (see Supplementary File 1, Table A, questions $\mathrm{OP} 1$ and OP2, for the original German wording).

\section{Specific closed and open-ended questions regarding the session (therapist questionnaire)}

Therapists were asked how many sessions patients had already had in the current modality and why that modality had been chosen (severity of the present condition, patient belonging to a risk group, patient request, other). Whether a specific treatment modality was requested by a patient may influence their acceptance of and experience with that modality. Therefore, we created a dichotomous variable patient request (yes/no). For some patients, more than one rationale for the allocation to a specific modality was reported. All patients for whom the therapist ticked the box patient request were allocated to the patient request group.

Therapists were also asked how they evaluated the current session modality compared to the normal modality for this specific patient (open-ended question): "For this patient, how do you evaluate the way the therapy sessions are currently conducted compared to the way they normally take place?" (see Supplementary File 1, Table A, question OT1, for the original German wording).

\section{Procedure}

Therapists informed eligible patients about the study at the end of a therapy session and provided them with the information sheet and their personal code. Patients were asked to complete the survey shortly after the session as the questions related to their experience of the therapy session; $70 \%$ of participants completed the survey on the same day. Data were collected through the online platform Qualtrics (Qualtrics, Provo, UT). Participants provided informed consent by ticking boxes to indicate that they had understood the aims of the study and their rights. The survey consisted of three questionnaires (SEQ, CSQ, and WAI-SR-P) and a number of questions on the patients' experience with the session and the treatment modality, how the pandemic affected them in general, and demographics.

The therapists also received an information sheet and were asked to provide informed consent, as the completion of the WAI meant that they, too, were participants in this study. The therapists' Qualtrics survey consisted of the WAI-SR-T, questions on their perception of the specific session, general questions regarding the session (reasons for modality chosen, number of sessions in the current modality) and questions regarding the patient (GAF score, psychiatric diagnoses). Therapists used the same code as the patient, which allowed matching the data. The code was encrypted before being saved to the data file.
Neither patients nor therapists received payment in return for their participation. The Cantonal Ethics Committee of Bern filed a letter of non-competence and stated no objection to the study (Req-2020-00421).

\section{Data analysis \\ Quantitative analyses}

Data were screened for outliers, and three scores that were more than 3 standard deviations from the mean (one each on the following scales: CSQ, SEQ depth, and WAI-SR-T bond) were winsorized and replaced with the next lowest or highest value. All statistical analyses were conducted with IBM SPSS 26 (IBM $^{\bullet}$ SPSS $^{\bullet}$ Statistics Version 26). A significance level of .05 was set, and all $p$ values are reported two-tailed. Because of the small sample size for the videoconferencing group, the results for this group are reported at a descriptive level only; for statistical analyses, the data from the videoconferencing group and the telephone group were collapsed into a telepsychiatry group. The main outcome variables were the SEQ, CSQ, WAI-SR-P, and WAI-SR-T. The sequential multiple regressions with modality as the predictor (dichotomized as face-to-face vs telepsychiatry) were adjusted for the variable therapist and the number of sessions the patient had already had in the current modality. A sequential multiple regression model was chosen to control for potential differences between the two therapists involved in the study and for the fact that the number of sessions that had already been attended in the relevant modality was higher for the telepsychiatric group than for the face-to-face group (see Table 1). According to post-hoc calculations with G*Power 3.1, achieved power to detect a medium effect with the current sample was good (.84). As all patients who were eligible and attended a treatment session during the relevant time period were approached, a priori power calculations would not have been meaningful for this study. For the analyses of patients' preferences, chi square statistics and frequencies were calculated.

\section{Qualitative analyses}

Patients' and therapists' responses to the open-ended questions were analysed for (1) factors that were perceived as positive (patient) or facilitated the session (therapist), and (2) factors that were perceived as negative (patient) or complicated the session (therapist). An inductive content analysis following the stages described by Elo and Kyngas [70] was conducted for each treatment modality group for responses from the patients and the therapists by one of the first authors. Content analysis allows large amounts of text to be organised into a smaller number of meaningful categories [71]. Topics referred to in several of the responses are reported in the result section. Quotes were translated from 
Table 1 Descriptive Information by Treatment Modality Group (Statistical Tests: Face-to-Face vs. Telepsychiatry Combined)

\begin{tabular}{|c|c|c|c|c|}
\hline & $\begin{array}{l}\text { face-to-face } \\
(n=29)\end{array}$ & $\begin{array}{l}\text { videoconferencing } \\
(n=11)\end{array}$ & $\begin{array}{l}\text { telephone } \\
(n=20)\end{array}$ & $p(\text { Cohen's } d)^{a}$ \\
\hline Number of sessions & $1.59(0.87)$ & $2.91(1.81)$ & $3.35(1.39)$ & $.000(1.30)^{\mathrm{b}}$ \\
\hline Gender (\% male) & $48.3 \%$ & $63.6 \%$ & $60.0 \%$ & $.311(0.26)^{c}$ \\
\hline Age & $39.62(11.22)$ & $38.00(9.89)$ & $38.95(12.26)$ & $.730(0.09)^{\mathrm{b}}$ \\
\hline Highest education & & & & $.067(-)^{d}$ \\
\hline Compulsory school & $3.4 \%$ & $9.1 \%$ & $5.0 \%$ & \\
\hline Apprenticeship & $27.6 \%$ & $27.3 \%$ & $25.0 \%$ & \\
\hline School-leaving examination & $24.1 \%$ & $18.2 \%$ & $30.0 \%$ & \\
\hline University degree & $44.8 \%$ & $45.5 \%$ & $40.0 \%$ & \\
\hline No of psychiatric diagnoses (incl. ADHD) & $1.66(0.61)$ & $1.55(0.52)$ & $1.80(0.77)$ & $.749(0.08)^{b}$ \\
\hline \multicolumn{5}{|l|}{ Comorbidities } \\
\hline F10-19 & $6.9 \%$ & $0.0 \%$ & $10.0 \%$ & $1.000(-)^{\mathrm{d}}$ \\
\hline F30-39 & $34.5 \%$ & $18.2 \%$ & $20.0 \%$ & $.185(0.35)^{\mathrm{C}}$ \\
\hline F40-49 & $20.7 \%$ & $36.4 \%$ & $15.0 \%$ & $.859(0.05)^{c}$ \\
\hline F60-69 & $0.0 \%$ & $0.0 \%$ & $20.0 \%$ & $.113(-)^{\mathrm{d}}$ \\
\hline GAF-score ${ }^{e}$ & $67.59(11.92)$ & $72.55(5.85)$ & $67.95(14.02)$ & $.519(0.17)^{b}$ \\
\hline COVID-19 high risk group & $10.3 \%$ & $0.0 \%$ & $15.0 \%$ & $1.000(-)^{\mathrm{d}}$ \\
\hline \multicolumn{5}{|l|}{ Impact of COVID-19 } \\
\hline change to everyday life & $3.62(1.05)$ & $4.00(1.33)$ & $4.10(1.25)$ & $.145(0.38)^{b}$ \\
\hline distress & $2.83(1.10)$ & $2.80(1.32)$ & $3.25(1.33)$ & $.395(0.22)^{b}$ \\
\hline fear & $2.38(1.18)$ & $2.60(0.84)$ & $2.70(1.17)$ & $.329(0.25)^{b}$ \\
\hline Allocation to treatment modality based on patient request & & & & $1.000(0.00)^{c}$ \\
\hline yes & $75.9 \%$ & $63.6 \%(77.8 \%)^{*}$ & $75.0 \%$ & \\
\hline no & $24.1 \%$ & $18.2 \%(22.2 \%)^{*}$ & $25.0 \%$ & \\
\hline
\end{tabular}

Note: The values represent either the mean, with the standard deviation reported in brackets, or the percentage of cases within the relevant group. School leaving examinations are similar to A levels in the UK and qualify the individual to study at a university. ${ }^{*}$ Information for 2 patients was missing in this group, which is why two percentages are reported. The first refers to $N=11$ (total cases), the second to $N=9$ (cases for which the information was available). ${ }^{\mathrm{a}}$ To check for statistically significant a priori differences between groups, the face-to-face group was compared to the collapsed telepsychiatry groups (telephone and videoconferencing) because of the small sample size in the videoconferencing group. ${ }^{\mathrm{b}}$ Two-samples $t$-test. ${ }^{\mathrm{C}} \mathrm{X}^{2}$ test. ${ }^{\mathrm{d}} \mathrm{Fisher}$ 's exact test. ${ }^{\mathrm{e}} \mathrm{As}$ data was provided by two therapists, a second $t$-test with $Z$ standardized GAF scores (standardization within therapist) was conducted, which yielded similar results, $t(58)=-0.62$, $p=.541, d=0.16$

German to English by one of the first authors and the other first author independently verified the translations of the quotes. The German original wording of the quotes included in the present paper can be seen from Table B in the Supplementary File 1.

\section{Results}

\section{Sample characteristics}

Mean age of the overall sample was $39.10(S D=11.19)$ years, $55 \%$ were male, and they had attended an average of $2.42(S D=1.49)$ sessions in the relevant modality, i.e. the modality in which their sessions took place at the time of data collection. In $75.9 \%$ of cases $(n=58$ as data for two cases were missing), the therapist reported that the modality had (also) been requested by the patient. The patients had 1.68 ( $S D=0.65$, range 1 to 3 ) psychiatric diagnoses on average (including the diagnosis of ADHD). The most common comorbidity was a F30-39 diagnosis (mood disorders; 27\%), followed by F40-49 (neurotic, stress-related and somatoform disorders; 22\%), F10-19 (substance use disorders; 7\%), and F60-69 (personality disorders, impulse-control and "habit" disorders; 7\%). Patients' average GAF score was $68.62(S D=$ 11.84). In terms of highest education, $5 \%$ had completed compulsory school, $27 \%$ had completed an apprenticeship, $25 \%$ had their school-leaving examination (a qualification to enter university), and $43 \%$ had a university degree. Details on sample characteristics by group can be seen from Table 1.

In terms of a priori differences between the groups, patients in the telepsychiatric group had attended statistically significantly more sessions in the present modality than patients in the face-to-face group, $t(47.94)=-5.03$, $p<.001, d=1.30$. All other group differences, including those on three potential confounding variables considered (age, questions regarding patients' experience with 
the COVID-19 pandemic, and GAF) did not reach statistical significance (see Table 1).

\section{Quantitative analyses SEQ, CSQ, WAI-SR-P, and WAI-SR-T}

Table 2 presents an overview of the mean scores for each of the three modalities and the standardized regression coefficients of the treatment modality variable (face-to-face vs. telepsychiatric session [telephone and videoconferencing combined]) adjusted for therapist and number of sessions for each of the sequential multiple regressions (see Supplementary File 1, Tables C-L, for the full regression tables). ${ }^{4}$ The telepsychiatric sessions were rated as significantly less deep than the face-to-face sessions $(B=-0.89, p=.001)$. While not statistically significant in step $1(B=0.01, p=.995)$, the predictor number of sessions approached significance after the predictor modality was introduced ( $B=0.17, p=.062$ ). We explored the association between number of sessions and SEQ depth in more detail. Individual scatterplots per group revealed small, non-significant associations between number of sessions and depth for the face-to-face group $(r=.26, p=.168)$ and the telephone group $(r=$ $.10, p=.672)$. By contrast, patients in the videoconferencing group tended to experience more depth to their session the more sessions they had already had in that modality $(r=.39, p=.243)$, an association that increased considerably after excluding an extreme value $(r=.68$, $p=.030$ ).

None of the other models reached statistical significance, i.e. treatment modality was not a statistically significant predictor for session smoothness, post-session positivity, satisfaction with the treatment received, or TA as rated by both patients and therapists.

\section{Patients' self-reported preferences}

Patients were asked whether they preferred the therapy sessions as they were before the COVID-19 pandemic, whether it made no difference to them, or whether they preferred the current sessions. Overall, 56.7\% reported that they felt it made no difference, followed by $38.3 \%$ who preferred the sessions as they were before the pandemic. A chi-square analysis comparing the face-to-face group and the telepsychiatry group revealed no statistically significant differences in responses (see Table 3).

\footnotetext{
${ }^{4}$ Sensitivity analyses comparing the face-to-face and telephone group were conducted to explore whether the results were affected by collapsing the two telepsychiatric modalities. Results were fairly similar to the main analyses, although two trends $(p<.10)$ emerged, one for WAI-SR-P bond and WAI-SR-T tasks, indicating lower ratings in the telephone condition than in the face-to-face condition for both instances. Telephone sessions were still rated as significantly less deep than face-to-face sessions $(B=-0.60, p=.049)$. The regression coefficients from the sensitivity analyses can be seen from Table $M$ in the Supplementary File 1.
}

An interesting observation was that the proportion of patients in the face-to-face group who felt that the current session was either no different or even better than the pre-COVID-19 sessions outweighed those who felt it was worse independently of whether they had been allocated on request or not, whereas in the telepsychiatric group this observation only applied to those who had requested the modality. Patients in the telepsychiatric group who had not requested the format were somewhat more likely to indicate the current sessions were worse than the pre-COVID-19 sessions. Note, however, that these descriptive observations are based on very small numbers per subgroup.

Participants were also asked about their treatment modality preferences (from most preferred to least preferred) if they were to have a choice among five options. ${ }^{5}$ The three groups differed in terms of their preferences, as can be seen from Fig. 1. The face-to-face group had a strong preference for on-site treatment, although a majority would prefer sessions in compliance with hygiene and distance rules. In the videoconferencing and telephone groups, for about half of the patients their current modality was their most preferred one, whereas the other half would prefer on-site sessions, mostly in compliance with hygiene and distance rules.

Descriptive analyses of the preferences within the faceto-face options revealed an overall preference for sessions following hygiene and distance rules only across the three groups, whereas no clear preference could be identified in terms of videoconferencing vs telephone sessions. In the face-to-face group, $58.6 \%$ preferred videoconferencing, whereas a much clearer picture emerged in both the videoconferencing group, in which $90.9 \%$ ranked videoconferencing higher than telephone, and the telephone group, where $80.0 \%$ ranked telephone higher than videoconferencing.

\section{Qualitative analyses \\ What did patients like and dislike about the specific session?}

Although patients were asked what they liked and disliked about the specific session modality, the vast majority of responses were more general and seemed to refer to the session as a whole.

In the face-to-face group, most of the positive aspects mentioned concerned either the therapist's behaviour (e.g. empathic, makes me feel taken seriously, friendly,

\footnotetext{
${ }^{5}$ Although therapists indicated for the majority of patients that the modality choice was based on or in line with the patients' request (see Table 1), a patient's request may not necessarily be identical with their preferred choice out of the five options (e.g. a patient may have experienced light symptoms but still wanted to attend the therapy session and therefore requested changing the format to a telepsychiatric session).
} 
Table 2 Questionnaire Means and Standard Deviations per Treatment Modality Group and Adjusted Standardised Regression Coefficients for Face-to-Face vs. Telepsychiatry Combined

\begin{tabular}{|c|c|c|c|c|c|}
\hline & $\begin{array}{l}\text { Face-to-face } \\
(n=29)\end{array}$ & $\begin{array}{l}\text { Videoconferencing } \\
(n=11)\end{array}$ & $\begin{array}{l}\text { Telephone } \\
(n=20)\end{array}$ & $\beta$ & $p$ \\
\hline \multicolumn{6}{|l|}{ SEQ } \\
\hline depth & $5.50(0.73)$ & $4.47(1.07)$ & $5.12(0.89)$ & -0.49 & .001 \\
\hline smoothness & $5.68(1.02)$ & $5.14(1.40)$ & $5.49(1.05)$ & -0.10 & .508 \\
\hline post-session positivity & $5.36(1.12)$ & $5.35(1.14)$ & $5.44(0.98)$ & 0.06 & .731 \\
\hline \multicolumn{6}{|l|}{ CSQ } \\
\hline total score & $3.75(0.30)$ & $3.63(0.38)$ & $3.71(0.30)$ & -0.23 & .143 \\
\hline \multicolumn{6}{|l|}{ WAI-SR-P } \\
\hline bond & $4.41(0.51)$ & $4.39(0.60)$ & $4.21(0.72)$ & -0.16 & .322 \\
\hline tasks & $3.99(0.52)$ & $3.75(0.68)$ & $3.78(0.68)$ & -0.27 & .084 \\
\hline goals & $3.95(0.58)$ & $4.14(0.49)$ & $3.93(0.77)$ & 0.08 & .612 \\
\hline \multicolumn{6}{|l|}{ WAI-SR-T } \\
\hline bond & $4.16(0.50)$ & $4.30(0.33)$ & $4.04(0.53)$ & -0.19 & .207 \\
\hline tasks & $3.75(0.45)$ & $3.93(0.37)$ & $3.61(0.50)$ & -0.19 & .221 \\
\hline goals & $3.62(0.47)$ & $3.91(0.44)$ & $3.53(0.39)$ & -0.03 & .844 \\
\hline
\end{tabular}

Note: The values represent the mean; the standard deviation is reported in brackets. The maximum scores for the SEQ subscales, the WAI-SR subscales, and the CSQ scale are 7, 5, and 4, respectively. The standardized beta coefficient for the predictor treatment modality (face-to-face or telepsychiatry [telephone and videoconferencing combined]; reference group: face-to-face), which is adjusted for therapist and number of sessions, is reported for each outcome variable together with the $p$ value of the regression coefficient

understanding) or the therapy session itself (e.g. an individual aspect that patients found particularly useful about the session or being able to talk to the therapist in general; e.g. Patient 30: "the time and therapeutic discussion we had"). The most common issue identified with the specific session was that the mask hampered communication (e.g. no feedback from facial expressions, therapist harder to understand acoustically), which was mentioned by about $17 \%$ of patients. For example, $\mathrm{Pa}-$ tient 32 wrote, "As for my therapist per se, (...), I am very satisfied. However, wearing a mask was a bit annoying because you can no longer see the facial expressions properly. But of course I understand the necessity of this measure." The remaining points raised concerned administrative issues (e.g. having to wait, temporary relocation of therapy sessions to a different building).

Positive aspects identified by the videoconferencing group were related either to the therapist/therapy session itself or to organisational advantages of the modality (e.g. Patient 25 wrote, "It is straightforward. If the doctor is running late, no time is lost because I can do something useful in the meantime rather than doing nothing in the waiting room."). Some patients also mentioned that they appreciated having the opportunity to conduct a videoconferencing session, felt it was uncomplicated or rated it even on a par with face-to-face sessions. The following negative aspects were mentioned by two patients (18\%) each: Technical problems (e.g. poor connection), lack of distance from everyday life (e.g. Patient 24 wrote, "( ...) Mutual presence was deeper at physical meetings. On my part, this may be due to the fact that, because there was no travelling to the therapy session, the change from home office to therapy session was too abrupt."), and specific issues with the modality (e.g. more difficult to concentrate or feeling less present).

The majority of the telephone group's positive comments again referred to the therapist or the therapy

Table 3 Preferences for pre-COVID-19 or Current Format by Treatment Modality Group (Statistical Tests: Face-to-Face vs. Telepsychiatry Combined)

\begin{tabular}{|c|c|c|c|c|}
\hline & $\begin{array}{l}\text { face-to-face } \\
(n=29)\end{array}$ & $\begin{array}{l}\text { videoconferencing } \\
(n=11)\end{array}$ & $\begin{array}{l}\text { telephone } \\
(n=20)\end{array}$ & $p$ (Cohen's $d)$ \\
\hline Pre-COVID-19 sessions vs current session & & & & $.917(0.14)$ \\
\hline pre-COVID-19 better & $37.9 \%$ & $27.3 \%$ & $45.0 \%$ & \\
\hline no difference & $55.2 \%$ & $72.7 \%$ & $50.0 \%$ & \\
\hline current better & $6.9 \%$ & $0.0 \%$ & $5.0 \%$ & \\
\hline
\end{tabular}

Note: For the Fisher's exact test, the face-to-face was compared to the collapsed telepsychiatry groups (telephone and videoconferencing) because of the small sample size of the videoconferencing group 


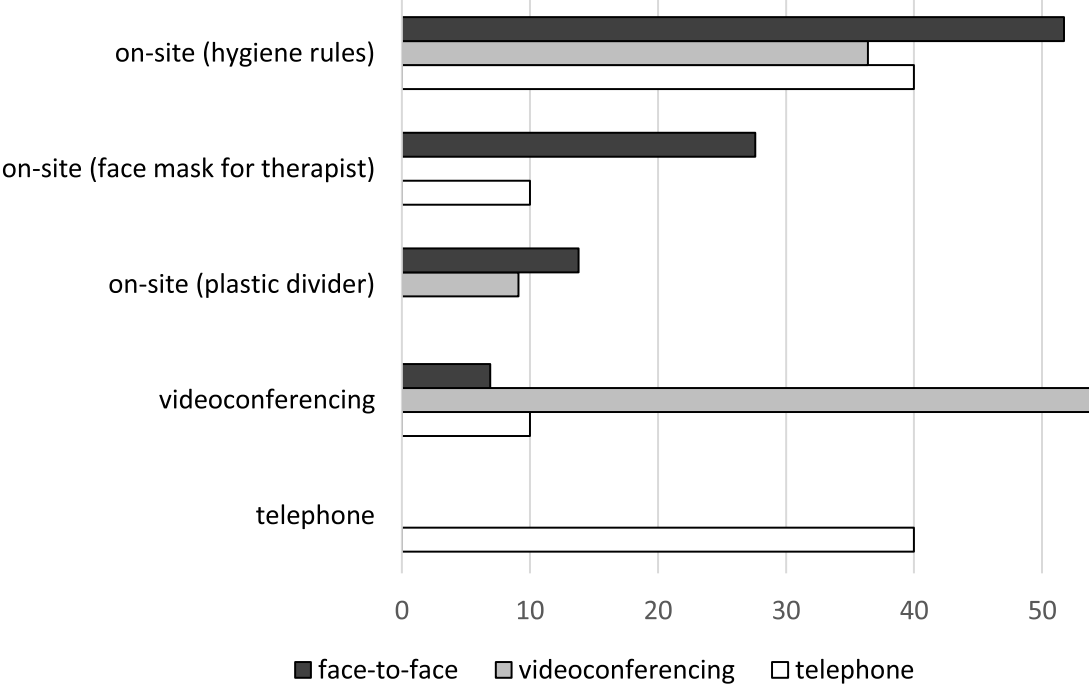

Fig. 1 Preferred Modality If Patients Had Free Choice Among Five Options. Note. This figure shows the percentage of patients in each group that indicated a specific option as their first choice

session. Some patients explicitly mentioned organizational advantages (e.g. saving time, no need to use public transport) or advantages that related to their symptoms (e.g. Patient 21 wrote, "The fact that the session is a conversation only without look and facial expressions also has advantages, because this way I am more focused on the content and not distracted or influenced by visual stimuli or by my therapist's behaviour.")". About 15\% of patients voiced concerns regarding the absence of visual input (e.g. Patient 28 wrote, "( ...) A lot of things that I can normally assess visually were missing. E.g., I couldn't tell from the facial expressions whether my question had been understood. This only became clear with the [therapist's] response. ( ...)"), felt that speaking over the phone was impersonal, or reported encountering administrative problems (e.g. poor sound quality). Circumstances identified as having the potential to make a telephone session more difficult were not being sufficiently familiar with the therapist and the absence of mimic feedback when discussing specific (personal) topics. Conversely, patients felt that a telephone session worked well to discuss medication or when there was already an established bond of trust with their therapist.

\section{Complicating and facilitating factors identified by the therapists}

Regarding face-to-face sessions, most of the complicating factors, which were mentioned for a little more than half of the patients, were related to communication difficulties caused by the face mask (e.g. reduced access to facial expression cues, acoustic communication problems, some patients feeling insecure or uncomfortable). For instance, Therapist B wrote for Patient 39, "Has initial difficulties coming to terms with the face mask, ( ...) keeps asking questions and thinks s(he) has not understood me acoustically. This interrupts the flow of conversation.". For about $40 \%$ of the patients, therapists felt that the sessions were fairly or fully comparable to the pre-COVID-19 sessions. A pre-existing bond of trust was reported to mitigate negative effects of wearing a mask, and therapists perceived the mask to be less of a problem for some patients than for others (e.g. Therapist A wrote for Patient 10, "Barrier due to mask because of significant reduction of mimic response and slight problems with comprehensibility - however, with a young, ( ...) reflective patient the session was sufficiently feasible.", although it was not possible to identify specific factors from the responses provided. Finally, in a small number of cases therapists reported positive effects of wearing a face mask as some patients seemed more attentive during the session as a result. Therapist B wrote for Patient 35, "Usually, this patient avoids eye contact. Under these circumstances, however, $s$ (he) maintained eye contact remarkably well (...)", and for Patient 40, "The impression is given that the covering of the region of the mouth made the patient pay more attention and not drifting off as [much as] usual.".

The issues most commonly identified with videoconferencing sessions were: not being able to get a full picture of the patient (both figuratively and literally speaking; e.g. limited access to body language cues; slightly more than half of the cases) and limitations in terms of therapeutic measures that could be employed (e.g. using whiteboards; raised for nearly half of the cases). Illustrating both points, Therapist A wrote for Patient 24, "limited due to the physical response not 
being completely visible and the considerable difficulties in completing specific tasks with the patient, (...) e.g. generating a to-do list (...)". Only few technical issues were reported. A mitigating factor mentioned by the therapists was the main goal of the session; for instance, the limitations of a videoconferencing session were less important for sessions that focused on medication rather than psychotherapeutic work.

In terms of telephone sessions, the issues raised most frequently were the lack of access to body language and facial expression cues and the associated limited insight into patients' affective or emotional reactions (about one third of the cases). For example, Therapist A wrote on the session with Patient 28, "Absence of emotional response or its equivalents in facial expressions and gestures. Patient is well known, but limitations were still significant because of it [the lack of visual information]". In some cases, therapeutic measures were limited, or the therapist felt that patients seemed more distracted than in regular face-to-face sessions. In addition, telephone sessions were perceived as less suitable for patients who were very unwell and/or needed to discuss difficult topics (e.g. Therapist B wrote for Patient 51, "As one parent recently passed away, it is difficult to discuss everything only over the phone. It would be better for the patient to leave his/her home to ease the burden [of the loss] as well"). Conversely, speaking over the phone worked well for sessions that focused on medication. For about one in three cases, therapists reported that they felt the sessions were at least fairly comparable to preCOVID-19 sessions and/or that the restrictions were not particularly problematic.

\section{Discussion}

This study sought to explore adult ADHD patients' and their therapists' experience of a therapy session during the COVID-19 pandemic. Our results indicate that patients who attended a face-to-face session with the therapist wearing a face mask experienced significantly more depth to their session than patients who received telepsychiatric care. Descriptively, depth was lowest in the video-conferencing group, but further exploratory analyses suggested that depth in that group increased with the number of sessions. Thus, over time the difference in session depth between modalities might decline, which would be in line with the findings reported by Morgan and colleagues [72], who did not observe statistically significant differences in session depth for telemental health vs face-to-face psychological or psychiatric services. We can only speculate about possible explanations for an (initially) lower session depth rating in the telepsychiatry group. Patients might experience initial technical difficulties, need time to adapt to the new format, or need time to become accustomed to discussing personal or intimate topics during a telepsychiatric therapy session.

No statistically significant effects of treatment modality were observed for any of the other outcome variables. Post-session positivity did not differ between modalities, which suggests that there were no major differences in the effects of face-to-face and telepsychiatric sessions on patients' post-session well-being. Also, patients' satisfaction with the services received did not differ depending on modality, and no statistically significant differences in patients' ratings of TA across the three conditions were observed. Although no direct comparison to preCOVID-19 TA is possible, the results do not suggest that one type of adjustment made because of the pandemic might be particularly detrimental to TA as perceived by patients. Contrary to some previous studies (see e.g. [33]), no statistically significant difference in therapist TA rating depending on treatment modality was observed either. This difference to previous findings might be due to the fact that the therapists in the present study already knew their patients. According to Simpson and Reid [33], lower TA ratings for telepsychiatry were observed mainly in the early stages of an intervention. The findings from our study indicate that the modality chosen may have little bearing on TA for both patients and therapists. In sum, we observed few differences between face-to-face sessions (with the therapist wearing a face mask) and telepsychiatric sessions for adult patients with ADHD, and it seems possible that the difference that was observed would decrease as the number of sessions in the new modality increases.

In line with other findings reported thus far, twothirds of all patients felt their sessions in the current treatment modality were not inferior to the pre-COVID19 modality, and there was no statistically significant difference in that respect between patients in the face-toface group and in the telepsychiatry group. If patients could choose freely from a number of options, however, over $60 \%$ of all patients ranked on-site treatment with adherence to hygiene rules rather than on-site treatment with the therapist wearing a face mask or using a plastic divider as their first choice for on-site treatment. Only a few of the patients in the face-to-face group opted for a telepsychiatric treatment modality as their first choice, whereas about half of the patients in the telepsychiatry group selected their current telepsychiatric treatment modality as their first choice. In terms of preferences for telephone vs videoconferencing, the majority of the patients in the telepsychiatric group clearly favoured their current modality, whereas no strong preference for one over the other was observed in the face-to-face group.

Despite the fact that the majority of patients reported preferring a face-to-face modality that did not involve the therapist wearing a face mask, only five (i.e. 17\%) of 
the patients in the face-to-face group actively mentioned issues related to the therapist wearing a mask, such as lack of facial expression cues or issues with acoustic comprehension, as something they disliked about their session. Rather, the results of the content analysis suggest that - across all conditions - patients' experience of the session was mainly shaped by positive aspects related to the therapist or the specific session. The therapists, by contrast, mentioned issues relating to their wearing a mask in about half of the cases. However, in a few cases they also reported that the absence of visual distractors (facial cues) seemed to have resulted in patients focusing more on the content of the session. Similar results were reported by Webb [73], who identified an increased treatment focus as a main theme in her qualitative study on clinicians' experiences with cognitive-behavioural therapy based telephone interventions. It is possible that therapists generally attach more importance to the question of the effects of the face mask than their patients. At least in the adoption of telephone interventions, the lack of non-verbal cues seems to be a key concern for therapists [34, 74]. Additionally, the open-ended questions for patients and therapists were formulated somewhat differently, which may have contributed to the therapists discussing the effects of wearing a mask more frequently. Either way, the fact remains that the vast majority of the patients in the face-to-face group did not feel the need to raise issues with the face mask.

In the telepsychiatric groups, in addition to the positive comments on the therapy session in general, patients additionally highlighted organisational advantages such as saving time. In the telephone condition, another advantage mentioned was the reduced distraction by visual information, which corresponds to findings from other research [75]. In the videoconferencing group, some emphasised a lack of distance from everyday life or raised specific issues with the modality, such as feeling less present. In the telephone group, three (15\%) patients raised issues related to the lack of visual cues and a similar number felt the telephone session was somewhat impersonal. Similar to the face-to-face group, the therapists were again much more concerned with the limitations of the telepsychiatric modalities, particularly the full or partial lack of visual cues, than were their patients. A key aspect was the therapists' perception that the lack of visual cues limited their ability to interpret the patient's experience. This seems to be a common concern among therapists. In a study by Olwill and colleagues [74], which surveyed Irish psychiatrist' experience of telephone consultations during the COVID-19 pandemic, this point was endorsed by 25 of the 26 respondents.

The responses to the open-ended questions on how the session was experienced also provided some insight into the circumstances under which a telepsychiatric session was considered more or less suitable. One aspect mentioned by both patients and therapists was session content. Telepsychiatric treatment was perceived to be more suitable if the session focused on discussing medication or other issues that were not too personal in nature. If more sensitive/intimate topics needed to be discussed, a face-to-face session was considered preferable. Therapists felt that telephone consultations were less appropriate for patients who were particularly unwell. Both patients and therapists also mentioned that, because of the limitations of telepsychiatry, some therapeutic methods could not be implemented (e.g. using white boards for to-do lists or plans), thereby highlighting another factor that may need to be considered when deciding on the modality of a session.

\section{Strengths, limitations, and future research}

One of the strengths of this study is that it sheds light on both patients' and therapists' experiences with different treatment settings and also provides us with qualitative information about these experiences. Moreover, to our knowledge it is the first study to investigate how an on-site session with the therapist wearing a face mask compares to telepsychiatric provision, both of which are potential adjustments that allow for continued treatment during a situation such as the COVID-19 pandemic. Yet, the generalisability of our results to other psychiatric disorders will need to be examined in future studies; depending on the predominant symptoms, patients may react differently to a scenario in which the therapist is wearing a face mask (see e.g. [9]). Moreover, recommendations regarding face masks have changed and future studies should examine whether the present results can be replicated if both therapist and patient wear a face mask during on-site sessions.

The focus on adult patients with ADHD is another strength of the study, as research on the suitability of telepsychiatric treatment for adult patients with ADHD is particularly scarce [52] and the various symptoms of ADHD, such as inattentiveness and organisational deficits, have distinct potential to interfere with this type of treatment modality. Due to ADHD's high prevalence in adults, often demanding continuous treatment, and its frequent presentation with severe psychiatric comorbidities, patients with ADHD are a particularly important group to study. This research offers a valuable contribution to the still understudied topic of adult ADHD. While our ADHD sample was comparable in terms of certain aspects such as comorbidity of major mood disorders (e.g. [76]), the comorbidity of substance abuse was lower than what has been reported in other studies [77, 78]. Moreover, the number of patients with high educational achievements was above average. These aspects should be taken into account in terms of the 
generalisability of the findings to other patients with ADHD. Also, future research should investigate whether our results can be replicated under non-pandemic conditions. Fear of contracting the virus may have resulted in on-site sessions being perceived as less desirable than under normal circumstances, which may have inflated patients' ratings of the telepsychiatric sessions.

Randomized allocation to treatment modality was not possible in this study. We identified a number of potential confounding variables and examined whether there were any group differences for these variables. Patient age was included because younger patients may be more familiar and confident with the use of telecommunication, which could have distorted the results in case of systematic differences between the three groups. The self-reported extent to which the patient was affected by the COVID-19 pandemic could be related to treatment modality (e.g. patients who were more affected were also more likely to stay at home and receive telepsychiatric care) and at the same time be associated with the outcome variables (e.g. patients who are more affected by the pandemic may feel more unwell, which may affect how they experience their therapy sessions). Finally, level of functioning could also be related to both treatment modality and our outcome variables. However, for none of these variables did we observe statistically significant differences between groups. Still, the findings of the present study are limited to situations in which patients (1) are already under treatment and familiar with their therapist, and (2) have a say in the choice of adjustment that is made in order to continue treatment during a situation such as the COVID-19 pandemic. It is likely that many patients requested a setting they thought they would feel comfortable with or suited them for one reason or another. Although this does not rule out that patients face difficulties with the modality they requested (e.g. problems with focusing during a telepsychiatric session), it is conceivable that patients who did not have a say in the first place may find it comparably more difficult to adapt to their new setting. While the subsamples were too small to examine this possibility further, descriptively, the telepsychiatric patients who had not requested their modality were the only subgroup in which the majority of patients indicated that the pre-COVID-19 sessions were better than the current sessions. Thus, future research should further explore the role of choice in the patients' acceptance of and experience with telepsychiatric treatment. Nonetheless, the circumstances in the study at hand reflect a real-life situation and our study provides valuable insights into how certain treatment options compare and what may need to be considered when deciding on which adjustments should be made.

The fact that all patients were treated by one of two therapists also limits the generalisability of the results. Future research using a broader sample of therapists will be needed to check the replicability of the results. Moreover, while the present study provides insight into the vital question of whether interim telepsychiatric treatment might affect TA differently from a face-to-face session with the therapist wearing a face mask, future studies should establish a baseline TA (i.e. TA during therapy sessions without any adjustments) to investigate how individual adjustments affect TA. In addition, the impact of a prolonged use of certain adjustments or modalities on patient and therapist experience remains unclear.

Finally, because of the small number of cases in the video-conferencing group, the groups were collapsed for the main analyses. While descriptive data in many cases did not suggest major differences between the telephone and the videoconferencing group for most variables, future studies should aim to include large samples to increase power to detect differences both between a face-to-face and a telepsychiatry group and also between different types of telepsychiatric settings. Our sensitivity analyses suggested that further examining TA may be of particular interest. The small number of cases was also the reason to not correct for multiple testing within the framework of this preliminary study.

\section{Implications for practice and conclusion}

Continuing psychiatric or psychotherapeutic treatment during the COVID-19 pandemic required significant changes to the way therapy sessions were conducted. First findings on the impact of such adjustments reported in the study at hand are encouraging; both options - on-site with the therapist wearing a mask and telepsychiatry - seem viable alternatives for continuing therapies during a situation such as the COVID-19 pandemic. Although telepsychiatric sessions were experienced as less deep by the participants, no differences were observed in post-session positivity, and the difference concerning depth might decline over time, especially in the videoconferencing condition. Also, no differences in terms of client satisfaction or TA as perceived by both patient and therapist were observed. While the majority of patients would prefer an on-site solution that does not involve the therapist wearing a face mask, patients' comments on the on-site session focused more on positive elements such as being able to attend the session/speak to their therapist rather than on issues related to the therapist wearing a face mask. Therapists seemed to be more concerned about potential negative impacts of the masks, and a similar observation was made regarding the lack of visual cues in telephone sessions.

When deciding on the modality or adjustment for a specific session, our findings suggest that it may be worthwhile for clinicians to consider the following two 
questions in addition to feasibility and patient preference: First, is the topic of the session highly personal in nature? If so, it might be worth discussing with the patient whether they would feel more comfortable with a face-to-face session. Conversely, if the topic is more general in nature (e.g. discussing medication), a telepsychiatric solution could be considered. Second, does the session contain therapeutic elements, such as drawing up plans and using whiteboards, that may be difficult or impossible to implement in a telepsychiatric setting and would not having access to these elements be particularly detrimental to the session (aims)? This is particularly relevant to sessions over the phone; advances in technology may make this question obsolete if videoconferencing is used and both parties are technically sufficiently skilled. Finally, some patients mentioned a lack of (physical and/or temporal) distance to their everyday life if the session was off-site. It may therefore be helpful to advise patients to take a short break (e.g. from working from home) prior to their telepsychiatric appointment or go to a specific location (e.g. separate room or place) when participating in a therapy session.

\section{Abbreviations}

ADHD: Attention-deficit/hyperactivity disorder; CSQ: Client Satisfaction Questionnaire; GAF: Global Assessment of Functioning; SEQ: Session Evaluation Questionnaire; TA: Therapeutic alliance; WAI-SR-P: Working Alliance Inventory short revised therapist version; WAI-SR-T: Working Alliance Inventory short revised patient version

\section{Supplementary Information}

The online version contains supplementary material available at https://doi. org/10.1186/s12888-021-03236-9.

Additional file 1: Table A. Overview of self-developed questions used in the study (German original wording and English translation). Table B. German Original Wording and English Translations of the Quotes Cited in the Publication. Table C Hierarchical Regression Results for SEQ Depth. Table D. Hierarchical Regression Results for SEQ Smoothness. Table E. Hierarchical Regression Results for SEQ Positivity. Table F. Hierarchical Regression Results for CSQ. Table G. Hierarchical Regression Results for WAI Bond (Patient). Table H. Hierarchical Regression Results for WAI Tasks (Patient). Table I. Hierarchical Regression Results for WAI Goals (Patient).

Table J. Hierarchical Regression Results for WAI Bond Therapist. Table K. Hierarchical Regression Results for WAI Tasks Therapist. Table L. Hierarchical Regression Results for WAI Goals Therapist. Table M. Sensitivity Analyses: Adjusted Standardised Regression Coefficients for Face-to-Face vs. Telephone Modality.

\section{Acknowledgments}

We would like to thank Heather Murray for copy-editing the manuscript.

\section{Authors' contributions}

HW/ML/AB/PB: conception of the study; HW/ML: ethics; HW: preparation of online questionnaires; $A B / P B$ : participant recruitment; HWNA: data analysis; HW/ML: writing of the first draft of the manuscript; $A B / E S / P B / S Y N A$ : writing and revisions. All authors read and approved the final version of the manuscript.

\section{Funding}

Not applicable.

\section{Availability of data and materials}

The datasets generated and analysed during the current study are available from the corresponding author on reasonable request in order to protect anonymity of the participants (in-depth responses to open-ended questions).

\section{Declarations}

Ethics approval and consent to participate

All participants provided electronic informed consent. The research was carried out in accordance with the Declaration of Helsinki. The study was submitted to the Cantonal Ethics Committee of Bern (Req-2020-00421) under the Federal Act on Research involving Human Beings. The Committee concluded that there were no concerns with the study with regards to the Human Research Act and filed a letter of non-competence. This declaration of non-competence corresponds to a declaration of no-objection under Swiss legislation regulating research involving human beings (see also e.g. $[79,80])$.

\section{Consent for publication}

Not applicable.

\section{Competing interests}

The authors declare that they have no competing interests.

\section{Author details}

${ }^{1}$ Department of Forensic Psychiatry, Institute of Forensic Medicine, University of Bern, Bern, Switzerland. ${ }^{2}$ Department of Psychiatry, Psychotherapy and Psychosomatics, Psychiatric Hospital, University of Zurich, Zurich, Switzerland. ${ }^{3}$ Psychology Services Limited, London, UK. ${ }^{4}$ Department of Psychology, Reykjavik University, Reykjavik, Iceland.

Received: 24 November 2020 Accepted: 21 April 2021

Published online: 05 May 2021

\section{References}

1. World Health Organization. Switzerland: WHO coronavirus disease (COVID19) dashboard. https://covid19.who.int/region/euro/country/ch. Acessed 30 Aug 2020.

2. The Federal Council. Ordinance on Measures to Combat the Coronavirus (COVID-19): COVID-19 Ordinance 2. 2020. https://www.admin.ch/opc/en/cla ssified-compilation/20200744/index.html. Accessed 18 Sept 2020.

3. Federal Office of Public Health. Erläuterungen zur Verordnung 2 vom 13. März 2020 über Massnahmen zur Bekämpfung des Coronavirus (COVID-19Verordnung 2), Fassung vom 25. März 2020. 2020. https://www.ag.ch/ media/kanton_aargau/themen_1/coronavirus_1/gemeinden_5/20200402_ GA-Infoschreiben_Sonderverordnung.pdf. Accessed 18 Sept 2020.

4. Liebrenz M, Weber J, Kieser U, Schleifer R. COVID-19 Pandemie: Psychiatrische Versorgung von Inhaftierten. Jusletter. 2020. https://doi.org/1 0.38023/a1ac1559-fc26-4a93-82e5-bce4aca0ecb2.

5. Foederatio Medicorum Psychiatricorum et Psychotherapeuticorum (FMPP). Aktuelle Informationen zur Coronavirus Pandemie. 2020. https://www. psychiatrie.ch/fmpp/stellungnahmen-und-publikationen/aktuelle-infos-zurcoronavirus-pandemie/. Accessed 3 Apr 2020.

6. Föderation der Schweizer Psychologinnen und Psychologen (FSP). FAQ Coronavirus. 2020. https://www.psychologie.ch/faq-coronavirus. Accessed 31 Mar 2020.

7. FMH Swiss Medical Association. Factsheet Telemedicine. 2020. https://www. fmh.ch/files/pdf24/factsheet-telemedizin.pdf. Accessed 23 Oct 2020.

8. Foederatio Medicorum Psychiatricorum et Psychotherapeuticorum (FMPP). High-Priority-Newsletter (Nr. 11). 2020. https://www.psychiatrie.ch/index. php?id=1293. Accessed 7 Oct 2020.

9. Mehta UM, Venkatasubramanian G, Chandra PS. The "mind" behind the "mask": assessing mental states and creating therapeutic alliance amidst COVID-19. Schizophr Res. 2020;222:503-4. https://doi.org/10.1016/j.schres.2 020.05.033.

10. Veluri N. Are masks impacting psychiatric inpatients' treatment? Psychiatry Res. 2020;293:113459. https://doi.org/10.1016/j.psychres.2020.113459.

11. Thirthalli J, Manjunatha N, Math SB. Unmask the mind! Importance of video consultations in psychiatry during COVID-19 pandemic. Schizophr Res. 2020; 222:482-3. https://doi.org/10.1016/j.schres.2020.06.005. 
12. Hüfner K, Hofer A, Sperner-Unterweger B. On the difficulties of building therapeutic relationships when wearing face masks. J Psychosom Res. 2020; 138:110226. https://doi.org/10.1016/j.jpsychores.2020.110226.

13. Marler H, Ditton A. "I'm smiling back at you": exploring the impact of mask wearing on communication in healthcare. Int J Lang Commun Disord. 2020; 56:205-14.

14. Wong CKM, Yip BHK, Mercer S, Griffiths S, Kung K, Wong MC-S, et al. Effect of facemasks on empathy and relational continuity: a randomised controlled trial in primary care. BMC Fam Pract. 2013;14:1-7.

15. Backhaus A, Agha Z, Maglione ML, Repp A, Ross B, Zuest D, et al. Videoconferencing psychotherapy: a systematic review. Psychol Serv. 2012; 9(2):111-31. https://doi.org/10.1037/a0027924.

16. Chan S, Parish M, Yellowlees P. Telepsychiatry today. Curr Psychiatry Rep. 2015;17(11):89. https://doi.org/10.1007/s11920-015-0630-9.

17. Hubley S, Lynch SB, Schneck C, Thomas M, Shore J. Review of key telepsychiatry outcomes. World J Psychiatry. 2016;6(2):269-82. https://doi. org/10.5498/wjp.v6.i2.269.

18. Guinart D, Marcy P, Hauser M, Dwyer M, Kane JM. Mental health care providers' attitudes toward telepsychiatry: a systemwide, multisite survey during the COVID-19 pandemic. Psychiatr Serv. 2021:appips202000441. https://doi.org/10.1176/appi.ps.202000441

19. Fletcher $T L$, Hogan JB, Keegan F, Davis ML, Wassef M, Day S, et al. Recent advances in delivering mental health treatment via video to home. Curr Psychiatry Rep. 2018;20(8):56. https://doi.org/10.1007/s11920-018-0922-y.

20. Sigurvinsdóttir $A L$, Jensínudóttir $K B$, Baldvinsdóttir KD, Smárason $O$, Skarphedinsson G. Effectiveness of cognitive behavioral therapy (CBT) for child and adolescent anxiety disorders across different CBT modalities and comparisons: a systematic review and meta-analysis. Nord J Psychiatry. 2020;74(3):168-80. https://doi.org/10.1080/08039488.2019.1686653.

21. Lamb T, Pachana NA, Dissanayaka N. Update of recent literature on remotely delivered psychotherapy interventions for anxiety and depression. Telemed e-Health. 2019;25(8):671-7. https://doi.org/10.1089/tmj.2018.0079.

22. Kuhn E, Owen JE. Advances in PTSD treatment delivery: the role of digital technology in PTSD treatment. Curr Treat Options Psychiatry. 2020;7(2):88102. https://doi.org/10.1007/s40501-020-00207-x.

23. Sunjaya AP, Mgt B, Chris A, Si M, Novianti D, MIPH M. Efficacy, patientdoctor relationship, costs and benefits of utilizing telepsychiatry for management of post-traumatic stress disorder (PTSD): a systematic review. Trends Psychiatry Psychother. 2020;42(1):102-10. https://doi.org/10.1590/223 7-6089-2019-0024.

24. Morland LA, Wells SY, Glassman LH, Greene CJ, Hoffman JE, Rosen CS. Advances in PTSD treatment delivery: review of findings and clinical considerations for the use of Telehealth interventions for PTSD. Curr Treat Options Psychiatry. 2020;7(3): 221-41. https://doi.org/10.1007/s40501-020-00215-x.

25. Jenkins-Guarnieri MA, Pruitt LD, Luxton DD, Johnson K. Patient perceptions of telemental health: systematic review of direct comparisons to in-person psychotherapeutic treatments. Telemed e-Health. 2015;21(8):652-60. https:// doi.org/10.1089/tmj.2014.0165.

26. Turgoose D, Ashwick R, Murphy D. Systematic review of lessons learned from delivering tele-therapy to veterans with post-traumatic stress disorder. J Telemed Telecare. 2018;24(9):575-85. https://doi.org/10.1177/1357633X1 7730443.

27. Lopez A, Schwenk S, Schneck CD, Griffin RJ, Mishkind MC. Technologybased mental health treatment and the impact on the therapeutic alliance. Curr Psychiatry Rep. 2019;21(8):76. https://doi.org/10.1007/s1192 0-019-1055-7.

28. Tryon GS, Blackwell SC, Hammel EF. A meta-analytic examination of clienttherapist perspectives of the working alliance. Psychother Res. 2007;17(6): 629-42. https://doi.org/10.1080/10503300701320611.

29. Horvath AO, Del Re A, Flückiger C, Symonds D. Alliance in individual psychotherapy. In: Norcross JC, editor. Psychotherapy relationships that work: Evidence-based responsiveness. New York: Oxford University Press; 2011. p. 25-69.

30. Ardito RB, Rabellino D. Therapeutic alliance and outcome of psychotherapy: historical excursus, measurements, and prospects for research. Front Psychol. 2011;2:270.

31. Berger $\mathrm{T}$. The therapeutic alliance in internet interventions: a narrative review and suggestions for future research. Psychother Res. 2017;27(5):51124. https://doi.org/10.1080/10503307.2015.1119908.

32. Norwood C, Moghaddam NG, Malins S, Sabin-Farrell R. Working alliance and outcome effectiveness in videoconferencing psychotherapy: a systematic review and noninferiority meta-analysis. Clin Psychol Psychother. 2018;25(6): 797-808. https://doi.org/10.1002/cpp.2315.

33. Simpson SG, Reid CL. Therapeutic alliance in videoconferencing psychotherapy: a review. Austr J Rural Health. 2014;22(6):280-99. https://doi. org/10.1111/ajr.12149.

34. Irvine A, Drew P, Bower P, Brooks H, Gellatly J, Armitage CJ, et al. Are there interactional differences between telephone and face-to-face psychological therapy? A systematic review of comparative studies. J Affect Disord. 2020; 265:120-31. https://doi.org/10.1016/j.jad.2020.01.057.

35. Demontis D, Walters RK, Martin J, Mattheisen M, Als TD, Agerbo E, et al. Discovery of the first genome-wide significant risk loci for attention deficit/ hyperactivity disorder. Nat Genet. 2019;51(1):63-75. https://doi.org/10.1038/ s41588-018-0269-7.

36. Polanczyk G, De Lima MS, Horta BL, Biederman J, Rohde LA. The worldwide prevalence of ADHD: a systematic review and metaregression analysis. Am J Psychiatry. 2007;164(6):942-8. https://doi.org/10.1176/ajp.2007.164.6.942.

37. Rösler M, Casas M, Konofal E, Buitelaar J. Attention deficit hyperactivity disorder in adults. World J Biol Psychiatry. 2010;11(5):684-98. https://doi. org/10.3109/15622975.2010.483249.

38. Biederman J, Mick E, Faraone SV. Age-dependent decline of symptoms of attention deficit hyperactivity disorder: impact of remission definition and symptom type. Am J Psychiatry. 2000;157(5):816-8. https://doi.org/10.1176/a ppi.ajp.157.5.816.

39. Biederman J. The course and persistence of ADHD throughout the life-cycle. In: Buitelaar JK, Kan CC, Asherson P, editors. ADHD in adults: characterization, diagnosis, and treatment. Cambridge: Cambridge University Press; 2011. p. 1-8. https://doi.org/10.1017/CBO9780511780752.002.

40. Kessler RC, Adler LA, Barkley R, Biederman J, Conners CK, Faraone SV, et al. Patterns and predictors of attention-deficit/hyperactivity disorder persistence into adulthood: results from the national comorbidity survey replication. Biol Psychiatry. 2005;57(11):1442-51. https://doi.org/10.1016/j. biopsych.2005.04.001.

41. Spencer TJ, Biederman J, Mick E. Attention-deficit/hyperactivity disorder: diagnosis, lifespan, comorbidities, and neurobiology. J Pediatr Psychol. 2007; 32(6):631-42. https://doi.org/10.1093/jpepsy/jsm005.

42. Wilens TE, Biederman J, Faraone SV, Martelon M, Westerberg D, Spencer TJ. Presenting ADHD symptoms, subtypes, and comorbid disorders in clinically referred adults with ADHD. J Clin Psychiatry. 2009;70(11):1557-62. https:// doi.org/10.4088/JCP.08m04785pur.

43. Simon V, Czobor P, Balint S, Meszaros A, Bitter I. Prevalence and correlates of adult attention-deficit hyperactivity disorder: meta-analysis. $\mathrm{Br} \mathrm{J}$ Psychiatry. 2009;194(3):204-11. https://doi.org/10.1192/bjp.bp.107.048827.

44. Bachmann CJ, Philipsen A, Hoffmann F. ADHS in Deutschland: Trends in Diagnose und medikamentöser Therapie. Dtsch Arztebl. 2017;114:141-8.

45. National Institute for Health and Care Excellence (NICE). Attention deficit hyperactivity disorder: Diagnosis and management. 2019. https://www.nice. org.uk/guidance/ng87/chapter/Recommendations\#managing-adhd. Accessed 27 Oct 2020

46. Volkow ND, Swanson JM. Adult attention deficit-hyperactivity disorder. New Engl J Med. 2013;369(20):1935-44. https://doi.org/10.1056/NEJMcp1212625.

47. Bernardi S, Faraone SV, Cortese S, Kerridge BT, Pallanti S, Wang S, et al. The lifetime impact of attention deficit hyperactivity disorder: results from the National Epidemiologic Survey on alcohol and related conditions (NESARC). Psychol Med. 2012;42(4):875-87. https://doi.org/10.1017/S003329171100153X.

48. Gjervan B, Torgersen T, Nordahl HM, Rasmussen K. Functional impairment and occupational outcome in adults with ADHD. J Attent Disord. 2012;16(7): 544-52. https://doi.org/10.1177/1087054711413074.

49. Kittel-Schneider S, Reif A. Adulte Aufmerksamkeitsdefizit -/Hyperaktivitätsstörung und Komorbidität: neue Befunde zu epidemiologischen und genetischen Faktoren. Nervenarzt. 2020;91(7):57582. https://doi.org/10.1007/s00115-020-00900-5.

50. Chen Q, Hartman CA, Haavik J, Harro J, Klungsøyr K, Hegvik T-A, et al. Common psychiatric and metabolic comorbidity of adult attention-deficit/ hyperactivity disorder: a population-based cross-sectional study. PLoS One. 2018;13(9):e0204516. https://doi.org/10.1371/journal.pone.0204516.

51. Canela C, Buadze A, Dube A, Eich D, Liebrenz M. Skills and compensation strategies in adult ADHD-A qualitative study. PLoS One. 2017;12(9): e0184964. https://doi.org/10.1371/journal.pone.0184964.

52. Spencer T, Noyes E, Biederman J. Telemedicine in the management of ADHD: literature review of telemedicine in ADHD. J Attent Disord. 2020 24(1):3-9. https://doi.org/10.1177/1087054719859081. 
53. Coetzer G. An empirical examination of the mediating influence of time management on the relationship between adult attention deficit and role stress. Pers Rev. 2016;45(4):681-706. https://doi.org/10.1108/PR-04-2015-0105.

54. Beauchaine TP, Ben-David I, Bos M. ADHD, financial distress, and suicide in adulthood: A population study. Sci Adv. 2020;6:eaba1551.

55. Arnon S, Reichel N. Closed and open-ended question tools in a telephone survey about "the good teacher": an example of a mixed method study. J Mix Methods Res. 2009;3(2):172-96. https://doi.org/10.1177/1558689808331036.

56. Scherr CL, Lindor NM, Malo TL, Couch FJ, Vadaparampil ST. A preliminary investigation of genetic counselors' information needs when receiving a variant of uncertain significance result: a mixed methods study. Genet Med. 2015;17(9):739-46. https://doi.org/10.1038/gim.2014.185.

57. Greysen SR, Harrison JD, Kripalani S, Vasilevskis E, Robinson E, Metlay J, et al. Understanding patient-centred readmission factors: a multi-site, mixedmethods study. BMJ Qual Saf. 2017;26(1):33-41. https://doi.org/10.1136/ bmjqs-2015-004570.

58. World Healt Organization. The ICD-10 classification of mental and behavioural disorders: clinical descriptions and diagnostic guidelines. World Health Organization. 1992. https://apps.who.int/iris/handle/10665/37958.

59. Deutsche Gesellschaft für Psychiatrie und Psychotherapie, Psychosomatik und Nervenheilkunde e.V. Langfassung der interdisziplinären evidenz- und konsenbasierten (S3) Leitlinie „Aufmerksamkeitsdefizit

-/Hyperaktivitätsstörung (ADHS) im Kindes-, Jugend- und Erwachsenenalter". 2018. https://www.dgppn.de/_Resources/Persistent/ 6f514fd31d75221054f1d880bda9637728e2b92d/Langfassung\%20ADHS\%2 OLeitlinie_080618.pdf. Accessed 27 Feb 2021.

60. Stiles WB, Reynolds S, Hardy GE, Rees A, Barkham M, Shapiro DA. Evaluation and description of psychotherapy sessions by clients using the session evaluation questionnaire and the session impacts scale. J Couns Psychol. 1994:41(2):175-85. https://doi.org/10.1037/0022-0167.41.2.175.

61. Hartmann A, Leonhart R, Hermann S, Joos A, Stiles WB, Zeeck A. Die Evaluation von Therapiesitzungen durch Patienten und Therapeuten. Diagnostica. 2013;59(1):45-59. https://doi.org/10.1026/0012-1924/a000078.

62. Attkisson CC, Zwick R. The client satisfaction questionnaire: psychometric properties and correlations with service utilization and psychotherapy outcome. Eval Program Plann. 1982;5(3):233-7. https://doi.org/10.1016/01497189(82)90074-X.

63. Schmidt J, Wittmann WW. ZUF-8: Fragebogen zur Messung der Patientenzufriedenheit. In: Geue K, Strauß B, Brähler E, editors. Diagnostische Verfahren in der Psychotherapie. Göttingen: Hogrefe; 2002. p. 392-6.

64. Kriz D, Nübling R, Steffanowski A, Wittmann WW, Schmidt J. Patientenzufriedenheit in der stationären Rehabilitation: Psychometrische Reanalyse des ZUF-8 auf der Basis multizentrischer Stichproben verschiedener Indikation. Z Med Psychol. 2008;17:67-79.

65. Hatcher RL, Gillaspy JA. Development and validation of a revised short version of the working Alliance inventory. Psychother Res. 2006;16(1):12-25. https://doi.org/10.1080/10503300500352500.

66. Wilmers F, Munder T, Leonhart R, Herzog T, Plassmann R, Barth J, et al. Die deutschsprachige Version des Working Alliance Inventory-short revised (WAI-SR)-Ein schulenübergreifendes, ökonomisches und empirisch validiertes Instrument zur Erfassung der therapeutischen Allianz. Klin Diagn Eval. 2008;1:343-58.

67. Munder T, Wilmers F, Leonhart R, Linster HW, Barth J. Working Alliance inventory-short revised (WAI-SR): psychometric properties in outpatients and inpatients. Clin Psychol Psychother. 2010;17(3):231-9. https://doi.org/10.1 002/cpp.658.

68. Munder T. Die deutschprachige Kurzversion des working Alliance inventory (unpublished master's thesis): Freiburg im Breisgau: Albert-Ludwigs Universität Freiburg; 2007.

69. American Psychiatric Association. Diagnostic and statistical manual of mental disorders. 4th ed. Washington DC: American Psychiatric Association; 1994.

70. Elo S, Kyngas H. The qualitative content analysis process. J Adv Nurs. 2008; 62(1):107-15. https://doi.org/10.1111/j.1365-2648.2007.04569.x

71. Hsieh H-F, Shannon SE. Three approaches to qualitative content analysis. Qual Health Res. 2005;15(9):1277-88. https://doi.org/10.1177/10497323052 76687.

72. Morgan RD, Patrick AR, Magaletta PR. Does the use of telemental health alter the treatment experience? Inmates' perceptions of telemental health versus face-to-face treatment modalities. J Consult Clin Psychol. 2008;76(1): 158-62. https://doi.org/10.1037/0022-006X.76.1.158.
73. Webb C. A qualitative study of the therapeutic alliance during thelephone cognitive behavioural therapy: clinicians' perspectives (doctoral thesis). UK: University of East Anglia; 2014.

74. Olwill C, Mc Nally D, Douglas L. Psychiatrist experience of remote consultations by telephone in an outpatient psychiatric department during the COVID-19 pandemic. Ir J Psychol Med. 2020:1-8. https://doi.org/10.1017/ ipm.2020.51.

75. Bee PE, Lovell K, Lidbetter N, Easton K, Gask L. You can't get anything perfect: "user perspectives on the delivery of cognitive behavioural therapy by telephone". Soc Sci Med. 2010;71(7):1308-15. https://doi.org/10.1016/j. socscimed.2010.06.031.

76. Kessler RC, Adler L, Barkley R, Biederman J, Conners CK, Demler O, et al. The prevalence and correlates of adult ADHD in the United States: results from the National Comorbidity Survey Replication. Am J Psychiatry. 2006;163(4): 716-23. https://doi.org/10.1176/ajp.2006.163.4.716.

77. Biederman J. Attention-deficit/hyperactivity disorder: a selective overview. Biol Psychiatry. 2005;57(11):1215-20. https://doi.org/10.1016/j.biopsych.2 004.10.020.

78. Kollins SH. ADHD, substance use disorders, and psychostimulant treatment: current literature and treatment guidelines. J Atten Disord. 2008;12(2):11525. https://doi.org/10.1177/1087054707311654.

79. Kropf-Staub S, Eicher M, Haslbeck J, Metzenthin P. Selbstmanagement bei Krebstherapien fördern: Das Symptom-Navi-Programm. Pflege. 2019;32(5): 267-76. https://doi.org/10.1024/1012-5302/a000696.

80. Fuchs A, Abegglen S, Berger-Estilita J, Greif R, Eigenmann H. Distress and resilience of healthcare professionals during the COVID-19 pandemic (DARV ID): study protocol for a mixed-methods research project. BMJ Open. 2020; 10(7):e039832. https://doi.org/10.1136/bmjopen-2020-039832.

\section{Publisher's Note}

Springer Nature remains neutral with regard to jurisdictional claims in published maps and institutional affiliations.

Ready to submit your research? Choose BMC and benefit from:

- fast, convenient online submission

- thorough peer review by experienced researchers in your field

- rapid publication on acceptance

- support for research data, including large and complex data types

- gold Open Access which fosters wider collaboration and increased citations

- maximum visibility for your research: over $100 \mathrm{M}$ website views per year

At BMC, research is always in progress.

Learn more biomedcentral.com/submissions 